\title{
EDUKASI IMD TERHADAP PEMBERIAN ASI EKSKLUSIF DI PUSKESMAS MAPILLI KABUPATEN POLEWALI MANDAR
}

\author{
Hamdan Nur ${ }^{1}$, Arlin Adam², Andi Alim ${ }^{2 凶}$, Ashriady ${ }^{3}$ \\ ${ }^{1}$ Program Pascasarjan Universitas Islam Makassar \\ ${ }^{2}$ Fakultas Kesehatan Masyarakat Universitas Pejuang Republik Indonesia \\ ${ }^{3}$ Jurusan Kebidanan Poltekkes Kemenkes Mamuju
}

\begin{tabular}{l} 
ARTICLE INFO \\
\hline Article history \\
Submitted : 2019-02-20 \\
Revised : 2019-11-05 \\
Accepted : 2019-12-21 \\
Keywords: \\
Education, \\
IMD \\
Exclusive breastfeeding
\end{tabular}

\section{Kata Kunci:}

Edukasi

IMD

ASI eksklusif

\begin{abstract}
The impact of not fulfilling exclusive breastfeeding in the first 6 months of a baby's life is the risk of malnutrition. Coverage of exclusive breastfeeding in Polewali Mandar is still low so there needs to be an increase in early breastfeeding initiation. This study aims to analyze the effect of Early Breastfeeding Initiation education on the provision of exclusive breastfeeding at the Mapilli Health Center in Mapilli District, Polewali Mandar Regency. This research is an analytical study with a cross-sectional design with a total sample of 86 people. Data collection was carried out by interviewing, observing, and documenting with data analysis techniques using SPSS 16 software. Results This study concluded (1) the influence of Early Initiation Early Education on exclusive breastfeeding (2) the absence of influence of family support for exclusive breastfeeding presence and absence of family support The mother continues to provide breastfeeding for her child (3) the absence of influence of the mother's work status on providing exclusive breastfeeding because the mother works or does not, the mother continues to breastfeed her child (4) from the Early Breastfeeding Initiation education, family support and work towards exclusive breastfeeding is only one that greatly influences the success of breastfeeding mothers, namely Early Breastfeeding Initiation education. This study suggests further research needs to be done by using better research designs such as prospective cohorts and larger sample sizes to reduce recall bias and be able to control for confounding factors and consider aspects of determinants of breastfeeding determination.
\end{abstract}

Dampak dari tidak terpenuhinya pemberian ASI eksklusif dalam 6 bulan pertama
kehidupan bayi adalah risiko malnutrisi. Cakupan pemberian ASI eksklusif di Polewali
Mandar masih rendah sehingga perlu ada peningkatan inisiasi menyusui dini. Penelitian
ini bertujuan untuk menganalisis pengaruh edukasi IMD terhadap pemberian ASI
eksklusif di Puskesmas Mapilli Kecamatan Mapilli Kabupaten Polewali Mandar
Penelitian ini merupakan penelitian analitik dengan desain cross-sectional, jumlah
sampel sebanyak 86 orang. Pengumpulan data dilakukan dengan wawancara, observasi,
dan dokumentasi dengan teknik analisis data menggunakan software program SPSS 16.
Penelitian ini menyimpulkan (1) adanya pengaruh edukasi IMD terhadap pemberian
ASI eksklusif (2) tidak adanya pengaruh dukungan keluarga terhadap pemberian ASI
eksklusif sebab adanya dan tidak adanya dukungan keluarga ibu tetap memberikan ASI
pada anaknya (3) tidak adanya pengaruh status pekerjaan ibu terhadap pemberian ASI
eksklusif sebab ibu bekerja atau tidak, ibu tetap memberi ASI pada anaknya (4) dari
edukasi IMD, dukungan keluarga dan pekerjaan terhadap pemberian ASI eksklusif
adalah hanya ada satu yang sangat mempengaruhi dengan adanya keberhasilan ibu
menyusui yakni edukasi IMD. Penelitian ini menyarankan perlu dilakukan penelitian
lebih lanjut dengan mengguanakan desain penelitian yang lebih baik seperti kohort
prospektif dan besar sampel yang lebih banyak untuk mengurangi recall bias dan dapat
mengendalikan faktor-faktor perancu serta mempertimbangkan aspek determinan
penentuan ASI.
penentuan ASI.

$\triangle$ Corresponding Author:

Andi Alim

Fakultas Kesehatan Masyarakat Universitas Pejuang Republik Indonesia

Telp. 085240911659

Email: andi_alimbagu@yahoo.co.id 


\section{PENDAHULUAN}

ASI Eksklusif adalah bayi tidak diberikan makanan selain ASI termasuk air putih, kecuali vitamin, mineral dan obat dalam bentuk oralit, tetes dan sirup, ASI perah juga dibolehkan (World Health Organization, 2010). Sedangkan air susu ibu adalah cairan hasil sekresi kelenjar payudara ibu, air susu ibu eksklusif adalah ASI yang diberikan kepada bayi sejak dilahirkan selama 6 bulan, tanpa menambahkan dan atau mengganti dengan makanan atau minuman lain. Tujuan pemberian ASI Eksklusif adalah menjamin pemenuhan hak bayi untuk mendapatkan ASI Eksklusif sejak lahir sampai dengan berusia 6 (enam) bulan dengan memperhatikan pertumbuhan dan perkembangannya. Selain itu untuk memberikan perlindungan kepada ibu dalam memberikan ASI Eksklusif kepada bayinya dan meningkatkan peran dan dukungan keluarga, masyarakat, pemerintah Daerah dan pemerintah pusat terhadap pemberian ASI Eksklusif (Kementrian Kesehatan Republik Indonesia, 2012).

Dampak tidak terpenuhinya ASI Eksklusif di 6 bulan awal kehidupan bayi salah satunya adalah risiko terjadinya gizi buruk. Kebutuhan gizi bayi lebih sedikit dari kebutuhan orang dewasa, namun jika dibandingkan perunit berat badan maka kebutuhan gizi bayi jauh lebih besar dari usia perkembangan lainnya. Makanan bergizi menjadi kebutuhan utama bayi pada proses tumbuh kembangnya (Grober, 2012).

Inisiasi Menyusu Dini atau disingkat sebagai IMD merupakan program yang sedang gencar dianjurkan pemerintah. Program ini dilakukan dengan cara meletakkan bayi yang baru lahir di dada ibunya dan membiarkan bayi ini merayap untuk menemukan puting susu ibu untuk menyusu. Proses penting yang terjadi adalah bayi akan mulai meremas-remas puting susu si ibu, bertujuan untuk merangsang supaya Air Susu Ibu (ASI) segera berproduksi dan bisa keluar. Pada kala III persalinan, pengisapan bayi pada payudara ibu merangsang pelepasan hormon oksitosin sehingga membantu involusi uterus dan membantu mengendalikan perdarahan dan membantu percepatan kala III (Wardani, 2009).

Menurut Efendi, (2010) dalam Trisnawati, (2017) menyatakan bahwa data WHO 2009 menunjukkan bahwa pada tiap 5 ibu bersalin terdapat 4 ibu yang tidak melakukan inisiasi menyusui dini mengalami prolog kala III persalinan (Trisnawati, 2017). Di Indonesia, kala III persalinan sering menjadi momok tersendiri. Pada tahun 2009 Terdapat 74 kasus dari tiap 100 kasus persalinan dengan prolong kala III persalinan. Rata-rata kasus tersebut disebabkan karena ibu bersalin tidak melakukan Inisiasi Menyusui Dini. Di Polindes Ny. Retno Indyahwati Desa Sedatiagung II Kecamatan Sedati Kabupaten Sidoarjo kejadian persalinan dengan prolong kala III persalinan masih mendominasi kasus persalinan. Setidaknya dari tiap 100 persalinan terdapat $65 \%$ ibu bersalin dengan prolong kala III persalinan. Salah satu sebabnya adalah tidak dilakukannya Inisiasi Menyusui Dini pada bayi baru lahir. Dari data tersebut terdapat $12 \mathrm{ibu}$ bersalin yang tidak melakukan Inisiasi Menyusui dini dan 8 ibu bersalin yang melakukan Inisiasi Menyusui Dini. Sedangkan untuk ibu bersalin kala III yang mengalami percepatan hanya $10 \mathrm{ibu}$, untuk ibu bersalin kala III yang melahirkan placenta secara normal ada 9 lbu dan yang mengalami perlamaan hanya 1 ibu saja.

Menurut Suari (2010) dalam Trisnawati, (2017) menyatakan pada bayi sehat, langkah awal yang dilakukan setelah proses persalinan berlangsung adalah inisiasi menyusu dini dengan cara mengeringkan dan membersihkan tubuh bayi dan kemudian meletakkannya di atas tubuh ibu. Kontak yang sesegera mungkin akan mengurangi perdarahan pada ibu dan menstabilkan suhu bayi. Dengan memposisikan bayi di perut ibu, bayi yang sehat akan segera merayap ke atas menuju puting payudara itu. Inisiasi Menyusui Dini pada kala tiga persalinan dimulai setelah lahirnya bayi dan berakhir dengan lahirnya plasenta dan selaput ketuban (Trisnawati, 2017).

Pada kala III persalinan pengisapan bayi pada payudara merangsang pelepasan hormon oksitosin sehingga membantu involusi uterus, membantu mengendalikan perdarahan sehingga mempercepat selesainya kala III persalinan (Wardani, 2009). Dampak tidak dilakukannya Inisiasi Menyusui Dini pada bayi adalah terjadinya kegagalan menyusui sehingga bayi tidak mendapatkan kolostrum yang bermanfaat untuk menurunkan angka kematian bayi. Disamping itu risiko tidak dilakukannya Inisiasi Menyusui Dini pada bayi adalah terjadinya kematian di jam pertama kelahirannya karena bayi tidak bisa 
menyesuaikan dengan lingkungan sekitarnya. Suari, (2010) dalam Trisnawati (2017) menyatakan Pada ibu, tidak dilakukannya Inisiasi Menyusui Dini berdampak terhadap prolong kala III persalinan sehingga dimungkinkan terjadinya resiko perdarahan, kelainan mengejan dan lain-lain (Trisnawati, 2017).

Bidan sebagai tenaga kesehatan hendaknya bisa memberikan bimbingan ketika persalinan berlangsung. Bimbingan itu bisa dengan menganjurkan untuk melakukan inisiasi menyusui dini, dan membantu melakukannya seperti dengan mendekatkan bayi ke pelukan ibu dan memberikan pemahaman kepada ibu tentang pentingnya Inisiasi Menyusui Dini. Selain itu secara berkala bidan diharapkan menitik beratkan penyuluhan kesehatan kepada konseling tentang pentingnya inisiasi menyusui dini.

Data Riskesdas menunjukkan cakupan ASI Eksklusif di Indonesia hanya 42\%. Hasil tersebut menunujukkan bahwa Indonesia berada diperingkat 49 dari 51 negara yang mendukung pemberian ASI Eksklusif. Sedangkan prevalensi gizi kurang pada balita $(\mathrm{BB} / \mathrm{U}<-2 \mathrm{SD})$ memberikan gambaran yang fluktuatif dari tahun 2007 sebesar 18,4\% menurun menjadi 17,9\% tahun 2010 kemudian meningkat lagi menjadi $19,6 \%$ pada tahun 2013 (Badan Litbangkes, 2013).

Persentase cakupan ASI Eksklusif di Sulawesi Barat tahun 2012 yaitu 32,1\%. Sedangkan kejadian gizi buruk dan kurang di Sulawesi Barat cukup tinggi merupakan urutan ke-3 dari 33 provinsi di Indonesia yaitu pada tahun 2007 (26\%), tahun 2010 (22\%), tahun 2013 (28\%) (Badan Litbangkes, 2013). Prevalensi keadaan gizi balita di Kabupaten Polewali Mandar yaitu gizi buruk 153 (0,37\%), gizi kurang $1.250(3,44 \%)$, gizi lebih 204 $(0,57 \%)$, BGM $870 \quad(2,44 \%)$ (Dinkes Kabupaten Polewali Mandar, 2015).

Data Puskesmas Kecamatan Mapilli Kabupaten Polewali Mandar dalam hal ini terdapat ibu hamil trisemester III sejumlah 46. hal ini sasaran pemberian edukasi terkait IMD pada ibu hamil dan bermuara pada pemberian ASI Eksklusif di Kecamatan Mapilli yang kini berdampak tidak hanya pada pertumbuhan dan perkembangan bayi melainkan juga kecerdasan bayi yang mempengaruhi. Sehingga telah dilakukan penghimbauan kepada seluruh masyarakat agar waspada terhadap kekurangan gizi dan stanting pada bayi karena Mapilli termasuk lima kecamatan yang rawan gizi buruk melalui kurangnya penggunaan ASI Eksklusif (Puskesmas Mapilli, 2015).

Penilaian status ASI Eksklusif diperlukan berbagai jenis parameter. Parameter tersebut antara lain: riwayat dan melakukan ASI Ekslusif Pengukuran tersebut tergantung dari tujuan pengukuran status ASI Eksklusif, apakah pengukuran status ASI Eksklusif sekarang atau mengukur status ASI Eksklusif yang berhubungan dengan masa lampau (Supariasa, Bakri, \& Fajar, 2002)

Banyak perempuan dari daerah pegunungan harus berjalan selama berjam-jam dari desa-desa terpencil ke Puskesmas. Hal ini mempersulit mereka dalam memeriksakan kehamilan secara rutin dan dalam mencari layanan kesehatan bagi bayi serta kesempatan untuk mendapatkan pengetahun tentang praktik menyusui dan perawatan yang baik untuk bayi mereka sangat kurang. Salah satu inisiatif untuk mengatasi masalah gizi di pegunungan Jaya Wijaya dengan mendirikan rumah tunggu (Devi Asmarani, 2015).

Dengan adanya berbagai permasalah tentang ASI dan ibu hamil di atas maka kami bermaksud untuk melakukan penelitian Edukasi pentingnya ASI pada ibu hamil terhadap IMD pada ASI Eksklusif Kecamatan Mapilli Kabupaten Polewali Mandar. Untuk mengetahui apakah rendahnya cakupan IMD merupakan salah satu faktor yang mempengaruhi masalah pemberian ASI.

Cakupan pemberian ASI Eksklusif di Polewali Mandar masih rendah sehingga perlu adanya peningkatan Inisiasi menyusui dini (IMD). Berdasarkan latar belakang di atas maka rumusan masalah penelitian ini adalah "Apakah ada pengaruh edukasi IMD terhadap pemberian ASI Eksklusif di Puskesmas Mapilli Kecamatan Mapilli Kabupaten Polewali Mandar?".

\section{METODE PENELITIAN Jenis dan Rancangan Penelitian}

Penelitian ini adalah observasional menggunakan rancangan cross sectional studi. Rancangan penelitian epidemiologi yang mencari pengaruh variabel bebas edukasi IMD, dukungan keluarga dan status pekerjaan ibu dengan variabel terikat (ASI Eksklusif).

\section{Tempat dan Waktu Penelitian}

Penelitian dilaksanakan di wilayah kerja Puskesmas Mapilli, Kabupaten Polewali 
Mandar. Waktu penelitian dilaksanakan Maret 2017.

\section{Populasi penelitian}

Populasi penelitian ini adalah semua ibu yang memiliki bayi yang berada di Kecamatan Mapilli Kabupaten Polewali Mandar pada tahun 2017 adalah 86 ibu.

\section{Cara pengambilan sampel}

Cara pengambilan sampel dilakukan dengan total sampling yang bertempat tinggal di wilayah Puskesmas yang lokasinya berada di Kecamatan Mapilli Kabupaten Polewali Mandar.

\section{Identifikasi Variabel Penelitian}

Variabel bebas adalah variabel yang mempengaruhi efek yaitu Edukasi IMD. Variabel terikat adalah variabel yang dipengaruhi oleh paparan yaitu ASI Eksklusif.

Variabel yang berpotensi sebagai variabel luar (confounding) dalam penelitian ini adalah pendidikan ibu, pekerjaan ibu dan dukungan keluarga.

\section{Cara Pengumpulan Data Data primer}

Data identitas dan karakteristik responden meliputi nama, usia/umur, jenis kelamin, riwayat pemberian ASI Eksklusif. Data ini diperoleh dengan menggunakan kuesioner yang ditanyakan kepada responden.

Data status ASI Eksklusif diperoleh dengan cara melihat KMS ibu tersebut. Data berat badan bayi diperoleh saat bayi berkunjung ke Posyandu. Data berat badan diukur menggunakan timbangan bayi yang telah ditera dan alat pengukur panjang badan dengan menggunakan microtoise dengan ketepatan $0,1 \mathrm{~cm}$ yang telah tersandarisasi. Data umur diperoleh dengan buku KIA/Akte kelahiran.

\section{Data Sekunder}

Data yang meliputi data Puskesmas, daftar ibu yang memberikan ASI Eksklusif pada bayinya setiap Desa dan data posyandu di Kecamatan Mapilli.

\section{Analisis Data}

Data dianalisis dengan menggunakan SPSS 16 program Analisis data dalam penelitian ini menampilkan 3 jenis analisis yaitu univariat, bivariat dan multivariat.
Analisis univariat menggunakan analisis deskriptif untuk menggambarkan karakteristik variabel yang diteliti menggunakan distribusi frekuensi dan persentase dari masing-masing kelompok variabel. Selanjutnya data ditampilkan dalam bentuk tabel dan narasi.

Analisis bivariat digunakan mengetahui pengaruh antara variabel bebas (IMD dan Edukasi) terhadap variabel terikat (ASI Eksklusif) dan variabel luar terhadap variabel terikat. Analisis yang digunakan adalah chi-square, pada tingkat kepercayaan $(\alpha=0,05)$. Untuk mengetahui kekuatan antara variabel bebas dan variabel terikat menggunakan Prevalence $(P)$ dengan Confidence interval (CI) 95\%.

Analisis multivariat digunakan dengan objek kajian pada statistika yang mempelajari perilaku dan hubungan antara dua atau lebih variabel dan digunakan untuk mengetahui pengaruh yang kuat diantar variabel tersebut. Analisis yang digunakan adalah regresi logistik, pada tingkat kepercayaan $(\alpha=0,05)$. Untuk mengetahui kekuatan antara variabel bebas dan variabel terikat serta variabel luar yang menggunakan Pravelence $(P)$ dengan Confidence interval (CI) $95 \%$.

\section{Etika Penelitian \\ Ethical Clearance}

Penelitian ini dilaksanakan atas izin dari Dinas Kesehatan Kabupaten Polewali Mandar serta Puskesmas yang terpilih serta surat kelayakan etik (ethical clearance) dari Dinas penanaman modal dan pelayanan terpadu satu pintu bidang penyelenggaraan pelayanan perizinan.

\section{Informed Consent}

Setiap responden yang ikut dalam penelitian ini diberi lembar persetujuan agar responden dapat mengetahui maksud dan tujuan penelitian serta dampak yang diteliti selama proses penelitian ini berlangsung. Jika responden bersedia ikut dalam penelitian ini maka harus menandatangani lembar persetujuan dan jika responden menolak untuk diteliti maka peneliti tidak akan memaksa dan tetap menghormati hak responden.

\section{Confidentiality}

Semua infomasi dan data yang berasal dari responden dipergunakan untuk keperluan penelitian serta dijaga kerahasiannya, dengan cara menuliskan nama samaran (inisial) dan 
alamat tidak lengkap (hanya ditulis Kota/Kabupaten dan nama Puskesmas).

\section{Benefit}

Pada penelitian ini peneliti berusaha memaksimalkan manfaat penelitian dan meminimalkan kerugian yang timbul akibat penelitian ini dengan menjaga etika selama pengambilan data dan tidak menyinggung perasaan responden.

\section{Justice}

Semua data dalam penelitian ini tanpa identitas/nama samaran, tidak digunakan untuk mempermalukan, menyalahkan atau menghakimi. Semua responden yang ikut dalam penelitian ini diperlakukan secara adil dan diberi hak yang sama.

\section{HASIL PENELITIAN}

\section{Karakteristik Subyek Penelitian}

Pada penelitian ini didapatkan 86 responden yang memenuhi kriteria inklusi dan eksklusi. Karena pada penelitian ini digunakan dua macam alat ukur yaitu 86 responden (100\%). Distribusi responden menurut dukungan keluarga, pekerjaan ibu, status pemberian ASI dan, Edukasi IMD.

Tabel 1. Distribusi responden Berdasarkan Karakteristik Status Pekerjaan dan Pendidikan Ibu di Puskesmas Mapilli. $n=86$

\begin{tabular}{lcc}
\hline Karakteristik & n & \% \\
\hline Status Pekerjaan & & \\
PNS & 4 & 4.7 \\
IRT & 76 & 88.4 \\
Petani & 2 & 2.3 \\
Guru & 3 & 3.5 \\
Wiraswasta & 1 & 1.2 \\
\hline Pendidikan & & \\
Rendah & 75 & 87.2 \\
Tinggi & 11 & 12.8 \\
\hline
\end{tabular}

Sumber: Data Primer, 2017

Dari tabel 1. diatas tersebut menunjukkan bahwa status pekerjaan ibu di dominasi dengan pekerjaan sebagai ibu rumah tangga (IRT) sebanyak 76 orang $(88,4 \%)$ dan status pekerjaan ibu yang paling rendah adalah wiraswasta sebanyak 1 orang (1.2\%). Sedangkan, untuk status pendidikan ibu yang paling besar dengan pendidikan rendah sebanyak 75 orang $(87,2 \%)$ dan yang paling rendah dengan pendidikan tinggi sebesar 11 orang $(12,8 \%)$.

\section{Analisis Univariat}

Pada Tabel 2. diatas menunjukkan status ASI Eksklusif di dominasi oleh ibu yang melakukan ASI Eksklusif sebesar 55 orang $(64,0 \%)$ dan ibu yang tidak melakukan ASI Eksklusif sebesar 31 orang (36\%). Sedangkan, untuk edukasi IMD di dominasi oleh ibu yang tidak mendapatkan edukasi sebanyak 45 orang $(52,3 \%)$ dan yang mendapatkan edukasi sebanyak 41 orang $(47,7 \%)$.

Dukungan keluarga di dominasi ibu yang tidak mendapatkan dukungan dari keluarga sebanyak 77 orang $(89,5 \%)$ dan ibu yang mendapatkan dukungan dari keluarga sebanyak 9 orang (10,5\%). Sedangkan, untuk pekerjaan ibu di dominasi ibu yang tidak bekerja sebesar 78 orang $(90,7 \%)$ dan ibu yang berstatus bekerja sebesar 8 orang $(9,3 \%)$.

Tabel 2. Distribusi Responden berdasarkan Pemberian ASI Eksklusif, Edukasi IMD, Dukungan Keluarga dan Pekerjaan Ibu di Puskesmas Mapilli

\begin{tabular}{lcc}
\hline Variabel & n & \% \\
\hline ASI Eksklusif & & \\
Tidak ASI Eksklusif & 31 & 36.0 \\
ASI Eksklusif & 55 & 64.0 \\
\hline Edukasi IMD & & \\
Tidak Mendapatkan Edukasi & 45 & 52.3 \\
Mendapatkan Edukasi & 41 & 47.7 \\
\hline Dukungan Keluarga & & \\
Tidak ada dukungan keluarga & 77 & 89.5 \\
Ada dukungan keluarga & 9 & 10.5 \\
\hline Pekerjaan Ibu & & \\
Bekerja & 8 & 9.3 \\
Tidak bekerja & 78 & 90.7 \\
\hline Sumber: Data Primer, 2017 & &
\end{tabular}

Sumber: Data Primer, 2017

\section{Analisis Bivariat}

Pada Tabel 3. menunjukan analisis hubungan antara ibu yang mendapatkan Edukasi IMD dengan pemberian ASI Eksklusif pada anak diperoleh bahwa ibu yang tidak mendapatkan edukasi dan tidak ASI Eksklusif sebesar 30 orang $(66,7 \%)$ dan ibu yang tidak mendapatkan edukasi dan ASI Eksklusif sebesar 15 orang $(33,3 \%)$. Sedangkan, ibu yang mendapat edukasi IMD dan tidak ASI Eksklusif sebesar 1 orang $(2,4 \%)$ dan ibu yang 
mendapat edukasi IMD dan ASI Eksklusif sebesar 40 orang $(97,6 \%)$. Hasil pengujian secara statistik chi-square diperoleh $\mathrm{p}=0,000$. Hal ini dapat disimpulkan bahwa terdapat hubungan yang signifikan antara edukasi IMD terhadap pemberian ASI Eksklusif pada anak $(\mathrm{p}=<0,05)$.

Pada Tabel diatas juga menunjukan analisis hubungan antara dukungan keluarga dengan pemberian ASI Eksklusif pada anak diperoleh bahwa ibu yang tidak mendapatkan dukungan keluarga dan tidak ASI Eksklusif sebesar 30 orang $(39,0 \%)$ dan ibu yang tidak mendapatkan dukungan dari keluarga dan ASI Eksklusif sebesar 47 orang (61,0\%). Sedangkan, ibu yang mendapatkan dukungan dari keluarga dan tidak ASI Eksklusif sebesar 1 orang $(11,1 \%)$ dan ibu yang mendapatkan dukungan dari keluarga dan ASI Eksklusif sebesar 8 orang $(88,9 \%)$. Hasil pengujian secara statistik chi-square diperoleh $\mathrm{p}=0,960$. Hal ini dapat disimpulkan bahwa tidak terdapat hubungan yang signifikan antara dukungan keluarga terhadap pemberian ASI Eksklusif pada anak $(\mathrm{p}=>0,05)$.

Pada Tabel 3. diatas menunjukan analisis hubungan antara status pekerjaan ibu dengan pembrian ASI Eksklusif pada anak diperoleh bahwa ibu yang bekerja dan tidak ASI Eksklusif sebesar 4 orang $(50,0 \%)$ dan ibu yang bekerja dan ASI Eksklusif sebesar 4 orang $(50,0 \%)$. Sedangkan, ibu yang tidak bekerja dan tidak ASI Eksklusif sebesar 27 orang $(34,6 \%)$ dan ibu yang tidak bekerja dan ASI Eksklusif sebesar 51 orang $(65,4 \%)$. Hasil pengujian secara statistik chi-square diperoleh $\mathrm{p}=0,310$. Hal ini dapat disimpulkan bahwa tidak terdapat hubungan yang signifikan antara status pekrjaan ibu terhadap pemberian ASI Eksklusif pada anak $(\mathrm{p}=>0,05)$.

Tabel 3. Pengaruh Edukasi IMD, Dukungan Keluarga dan Pekerjaan Ibu terhadap Pemberian ASI Eksklusif di Puskesmas Mapilli

\begin{tabular}{|c|c|c|c|c|c|c|c|}
\hline \multirow{3}{*}{ Variabel } & \multicolumn{4}{|c|}{ ASI Eksklusif } & \multirow{2}{*}{\multicolumn{2}{|c|}{ Total }} & \multirow{3}{*}{ P-Value } \\
\hline & \multicolumn{2}{|c|}{ Tidak ASI Eksklusif } & \multicolumn{2}{|c|}{ ASI Eksklusif } & & & \\
\hline & $\mathbf{n}$ & $\%$ & $\mathbf{n}$ & $\%$ & $\mathbf{n}$ & $\%$ & \\
\hline Edukasi IMD & & & & & & & \multirow{3}{*}{0.000} \\
\hline Tidak mendapat edukasi & 30 & 66.7 & 15 & 33.3 & 45 & 100.0 & \\
\hline Mendapat edukasi & 1 & 2.4 & 40 & 97.6 & 41 & 100.0 & \\
\hline \multicolumn{8}{|l|}{ Dukungan Keluarga } \\
\hline Tidak ada dukungan keluarga & 30 & 39.0 & 47 & 61.0 & 77 & 100.0 & \multirow{2}{*}{0.960} \\
\hline Ada dukungan keluarga & 1 & 11.1 & 8 & 88.9 & 9 & 100.0 & \\
\hline \multicolumn{8}{|l|}{ Status Pekerjan Ibu } \\
\hline Bekerja & 4 & 50.0 & 4 & 50.0 & 8 & 100.0 & \multirow{2}{*}{0.310} \\
\hline Tidak bekerja & 27 & 34.6 & 51 & 65.4 & 78 & 100.0 & \\
\hline
\end{tabular}

Sumber: Data Primer, 2017

\section{Analisi Multivariat}

Pada Tabel 4. diatas menunjukkan bahwa, edukasi IMD pada ASI Eksklusif yakni dengan jumlah beta 428 , B adalah 0.412 , std error adalah $0.078, \mathrm{t}$ adalah 5.269 , sig adalah $0.000, \mathrm{R}$ adalah 630 dukungan keluarga pada
ASI Eksklusif yakni dengan jumlah beta -083 dan nilai $\mathrm{B}$ adalah -131 , std error $0.162, \mathrm{t}$ adalah -807 , sig adalah 0.422 edukasi IMD memiliki nilai $\mathrm{r}$ dengan $630 \%$ dengan ini menunjukkan bahwa ada pengaruh pada edukasi IMD terhadap ASI Eksklusif.

Tabel 4. Pada Edukasi IMD dan Dukungan Keluarga terhadap Pemberian ASI Eksklusif

\begin{tabular}{ccccccc}
\hline $\begin{array}{c}\text { Pemberian ASI } \\
\text { Eksklusif }\end{array}$ & B & Std Error & Beta & t & Sig & R \\
\hline Edukasi IMD & 0.412 & 0.078 & 0.428 & 5.269 & 0000. & 630 \\
Dukungan keluarga & -.131 & 0.162 & -0.83 & -807 & .422 & \\
\hline Sumber: Data Primer & 2017 & & & & &
\end{tabular}

Sumber: Data Primer, 2017 


\section{PEMBAHASAN}

Hasil penelitian ini menunjukkan bahwa adanya pengaruh antara variabel edukasi IMD dengan pemberian ASI Eksklusif, dan tidak adanya pengaruh antara dukungan keluarga dan pekerjaan ibu, terhadap pemberian ASI Eksklusif di Puskesmas Mapilli Kecamatan Mapilli Kabupaten Polewali Mandar.

\section{Peran edukasi IMD dengan pemberian ASI ekskusif}

Hasil analisis penelitian ini menunjukkan bahwa ada pengaruh edukasi IMD terhadap pemberian ASI Eksklusif di Puskesmas Mapilli Kecamatan Mapilli Kabupaten Polewali Mandar. yang berarti ibu mendapatkan edukasi IMD sangat mempengaruhi pemberian ASI Eksklusif

ASI Eksklusif akan berdampak pada berat badan dan panjang bayi, Marques et al., (2004) dalam penelitiannya yang berjudul Growth of exusvery breasfeed Infants in the first 6 months of life menemukan bayi yang menerima ASI secara eksklusif akan mencapai berat badan dua kali lipat berat badan lahir pada usia 4 bulan dan akan melambat setelah itu. Adanya perbedaan dalam penelitian ini dengan penelitian lainnya disebabkan adanya perbedaan metode penelitian, jumlah sampel, analisis data serta perbedaan lokasi/negara penelitian (Marques, Lopez, \& Braga, 2004). Penelitian ini didukung pula hasil penelitian yang dilakukan oleh Nilakesuma et al., (2015) bahwa ada pengaruh antara edukasi IMD dengan ASI Eksklusif dengan nilai p: 0.764 Penelitian ini menggunakan metode cross sectional di Wilayah kerja Puskesmas dengan uji analisis statistik chi square. Pada penelitian ini yang diteliti adalah ibu Sedangkan pengetahuan ibu mengenai kesehatan tidak diteliti. Hal ini bisa menjadi salah satu faktor yang menyebabkan hasil penelitian tidak bermakna (Nilakesuma, Jurnalis, \& Rusjdi, 2015).

\section{Peran Dukungan keluarga terhadap pemberian ASI Eksklusif}

Hasil analisis penelitian ini menunjukkan bahwa tidak ada pengaruh antara dukungan keluarga terhadap pemberian ASI Eksklusif karena nilai $\mathrm{p}=0.96$. hal ini menunjukkan bahwa tidak adanya pengaruh dukungan dan tidak adanya dukungan tetap si ibu akan memberikan ASI Eksklusif. Penelitian ini didukung pula hasil penelitian bahwa ada pengaruh antara dukungan keluarga dengan ASI Eksklusif dengan nilai p: 0.96 dengan menggunakan metode cross sectional di Wilayah kerja Puskesmas dengan uji t. Hasil analisis penelitian ini menunjukkan bahwa tidak ada pengaruh antara dukungan keluarga dengan pemberian ASI Eksklusif Hal ini sejalan dengan penelitian Mery Susanty dkk, (2012) bahwa status pemberian ASI Eksklusif tidak ada pengaruh dengan kejadian gizi buruk, yang berarti balita yang mendapatkan dan tidak mendapatkan ASI Eksklusif memiliki peluang yang sama untuk menderita gizi buruk, ketidak adanya hubungan tersebut bisa disebabkan oleh beberapa hal seperti kekurang mampuan Ibu merawat bayinya, sanitasi lingkungan yang tidak sehat, frekuensi serta durasi pemberian ASI yang tidak tepat (Susanty, Kartika, Hadju, \& Alharini, 2012).

Hal ini didukung pula penelitian yang dilakukan oleh Muchina and Waithaka, (2010) bahwa tidak ada hubungan yang signifikan antara praktek pemberian ASI dan wasting, namun pada penelitian tersebut tidak dilakukan kontrol umur terhadap wasting (Muchina \& Waithaka, 2010).

Penelitian yang bertolak belakang dengan peneliti yang dilakukan oleh Giri, (2013). Berdasarkan hasil uji korelasi dengan metode cross sectional diketahui bahwa ada hubungan yang bermakna antara pemberian ASI Eksklusif dengan status gizi balita usia 624 bulan menggunakan parameter berat badan terhadap tinggi badan dengan nilai $\mathrm{p}<0.001$, perbedaan tersebut bisa disebabkan oleh beberapa hal yakni perbedaan tehnik pengambilan sampel (simple random sampling), besar sampel (78 orang), dan pengelompokan status gizi bayi berdasarkan BGM (Bawa Garis Merah) dan tempat penelitian berada di Kelurahan Buleleng, Bali (Giri, Muliarta, \& Wahyuni, 2013).

Bayi yang mendapatkan ASI secara eksklusif kemungkinan untuk menderita wasting (kurus) lebih rendah dibandingkan dengan bayi yang mendapat ASI secara eksklusif kurang dari 6 bulan (Jannah, 2016)

ASI Eksklusif akan berdampak pada berat badan dan panjang bayi, Menurut Marques et al., (2004) dalam penelitiannya yang berjudul Growth of exusvery breasfeed Infants in the first 6 months of life menemukan bayi yang menerima ASI secara eksklusif akan 
mencapai berat badan dua kali lipat berat badan lahir pada usia 4 bulan dan akan melambat setelah itu. Adanya perbedaan dalam penelitian ini dengan penelitian lainnya disebabkan adanya perbedaan metode penelitian, jumlah sampel, analisis data serta perbedaan lokasi/negara penelitian (Marques et al., 2004).

\section{Peran pekerjaan ibu terhadap pemberian ASI Eksklusif}

Berdasarkan analisis bivariat antara pekerjaan ibu dengan variabel ASI Eksklusif, hasil penelitian menunjukkan bahwa tidak ada pengaruh antara ASI Eksklusif dengan pekerjaan ibu, tersebut tidak berpengaruh secara langsung terhadap status ASI Eksklusif.

Penelitian ini didukung pula hasil penelitian yang dilakukan bahwa tidak adapengaruh antara pekerjaan ibu dengan ASI Eksklusif dengan nilai $p$ : 0.451 dengan menggunakan metode Cross Sectional di Wilayah kerja Puskesmas. Hasil analisis penelitian ini menunjukkan bahwa tidak ada hubungan antara pemberian ASI Eksklusif dengan pekerjaan ibu. Hal ini sejalan dengan penelitian yang dilakukan Wahdah et al., (2012) bahwa tidak ada hubungan antara status pekerjaan ibu dengan pemberian ASI dengan nilai $\mathrm{p}<0.05$ (0.07) sedangkan penelitian yang dilakukan Sawadogo et al., (2006) ditemukan ibu sibuk bekerja terhadap pemberian ASI memiliki hubungan positif dengan kategori indeks pemberian makanan pada bayi dan balita antara anak-anak berusia 6-11 dengan nilai $\mathrm{p}=$ 0.03 (Wahdah, Juffrie, \& Huriyati, 2016), (Sawadogo et al., 2006).

Penilaian status pekerjaan dengan pemberia ASI dianggap sebagai indikator yang baik untuk menilai pemberian ASI dan kesehatan bayi dan anak-anak. Stunting (pendek) menunjukkan pertumbuhan yang rendah dan efek kumulatif dari kekurangan nutrisi baik makro maupun mikro dalam waktu yang lama. Pada penelitian yang dilakukan oleh Melaku et al., (2003) menunjukkan bahwa frekuensi pemberian ASI, jumlah yang diberikan kepada bayi merupakan faktor penting yang berhubungan dengan tumbuh kembang bayi. Bayi yang ASI Eksklusif yang relatif lebih banyak dan lebih tinggi dari mereka yang tida asi lebih sedikit $(<600 \mathrm{ml} / \mathrm{d})$, Usia pengenalan puting ibu kurang terkait dengan pemberian ASI serta (zing dan konsentrasi kalsium ASI) yang rendah juga memberikan kontribusi terjadinya peminatan ASI pada bayi (Umeta, West, Verhoef, Haidar, \& Hautvast, 2003).

Penelitian yang dilakukan oleh Hidayah et al., (2013) didapatkan adanya hubungan bermakna antara ASI Eksklusif dengan pekerjaan di Kota Yogyakarta dengan nilai $\mathrm{p}=0,03 ; \quad \mathrm{OR}=1,74 \quad(\mathrm{CI}=1,04-3.04)$. Sehingga dapat dikatakan anak yang tidak mendapatkan ASI Eksklusif berisiko 1,74 kali dibandingkan anak yang mendapatkan ASI Eksklusif. Analisis multivariat dengan mengontrol variabel luar dan status menyusu menunjukkan hubungan ASI Eksklusif dengan kejadian peminatan ASI pada anak usia 6-24 bulan di Kota Yogyakarta menjadi tidak bermakna $\mathrm{p}=0,49 ; \quad \mathrm{OR}=1,23 \quad$ (CI: $0.68-2.24)$ sehingga dapat dikatakan anak yang tidak mendapatkan ASI Eksklusif berisiko 1,23 kali dibandingkan anak yang mendapatkan ASI Eksklusif (Hidayah, 2013).

Pemberian ASI secara eksklusif pada bayi selama 6 bulan dapat menyelamatkan 25 kasus gizi buruk per 1000 bayi. Setiap sembilan bayi yang diberikan ASI secara eksklusif dapat menyelamatkan 1 kasus gizi buruk (Pascale, Laure, \& Enyong, 2007). ASI merupakan makanan yang higienis, murah, mudah diberikan dan sudah tersedia bagi bayi. ASI dan plasma memiliki konsentrasi ion yang sama sehingga bayi tidak memerlukan cairan atau makanan tambahan (Brown, 2016).

ASI Eksklusif yang diberikan terlalu lama secara otamatis akan menunda pemberian MP-ASI. Akibatnya, anak akan menerima asupan zat gizi yang tidak adekuat untuk pertumbuhan dan perkembangannya. Setelah usia 6 bulan, pemberian ASI harus didampingi oleh MP-ASI karena ASI saja sudah tidak mampu mencukupi kebutuhan energi dan zat gizi (Candra, Puruhita, \& Susanto, 2011).

Berdasarkan analisis bivariat antara edukasi IMD dengan variabel luar yakni dukungan keluarga dan pekerjaan ibu, hasil penelitian menunjukkan bahwa tidak ada pengaruh antara dukungan keluarga terhadap pemberian ASI Eksklusif sedangkan ada pengaruh antara edukasi IMD terhadap pemberian ASI Eksklusif. Variabel luar tersebut tidak berpengaruh secara langsung terhadap pemberian ASI bayi sebagaimana rumusan faktor yang menyebabkan gizi kurang yang disepakati Persatuan Ahli Gizi Indonesia 
(Persagi) pada tahun 1999 (Supariasa et al., 2002).

Hal ini sejalan dengan penelitian yang dilakukan oleh Nur Afia Amin, (2015) bahwa variabel yang paling berpengaruh terhadap pemberian ASI Eksklusif yaitu edukasi IMD (p: 0.01) sedangkan variabel pekerjaan, pendidikan, pendapatan dan pengeluaran, jumlah anggota keluarga tidak menunjukkan hasil yang bermakna terhadap pemberian ASI Eksklusif (Amin, 2015).

Penelitian ini didukung pula hasil penelitian yang dilakukan oleh Nilakesuma et al., (2015) bahwa tidak ada pengaruh antara tingkat pendidikan ibu dengan pemberia ASI Eksklusif dengan nilai p: 0.768 dan tidak ada hpengaruh yang bermakna antara status ekonomi keluarga dengan status gizi dengan nilai p: 0,524. Penelitian ini menggunakan metode Cross Sectional Analytic di Wilayah kerja Puskesmas Padang Pasir dengan uji analisis statistik Chi Square. Pada penelitian ini yang diteliti adalah tingkat pendidikan yang telah ibu selesaikan secara formal. Sedangkan pengetahuan ibu mengenai kesehatan tidak diteliti. Hal ini bisa menjadi salah satu faktor yang menyebabkan hasil penelitian tidak bermakna (Nilakesuma et al., 2015).

Penelitian yang dilakukan oleh Paramashanti et al., (2015) bahwa anak yang berasal dari keluarga dengan status ekonomi sangat miskin, miskin dan menengah masingmasing memiliki resiko (1,96; CI: 1,53-2,52), $(1,62$; CI: $1,30-2,03)$ dan $(1,32$; CI: $1,06-1,64)$ kali lebih tinggi untuk menjadi stunting apabila dibandingkan dengan anak yang berasal dari keluarga kaya. Pendapatan keluarga yang memadai akan menunjang perkembangan status gizi bayi karena orang tua mampu memenuhi semua kebutuhan bayi (Paramashanti, Hadi, \& Gunawan, 2015). Status gizi pada anak sangat dipengaruhi oleh umur sebagaimana penelitian yang dilakukan oleh Madise et al., (1999) dengan uji korelasi pemberian ASI Eksklusif pada anak dan pada keluarga dengan latar belakang dan geografis yang sama serta ditemukan pula bahwa status gizi dipengaruhi oleh faktor sosial ekonomi dan karakteristik individu yang bervariasi disetiap Negara (Madise, Matthews, \& Margetts, 1999).

Penyebab langsung masalah gizi adalah kecukupan makanan dan keadaan kesehatan. Adapun penyebab tidak langsung meliputi ketahanan makanan keluarga, asuhan bagi ibu dan anak, pemanfaatan pelayanan kesehatan dan sanitasi lingkungan. Dalam hal tersebut, pendidikan seorang ibu/pengasuh dan keluarga menjadi penghubung yang mempengaruhi penyebab tidak langsung. Sedangkan penyebab yang paling mendasar dari tumbuh kembang anak adalah masalah struktur politik dan ideologi, struktur ekonomi yang dilandasi potensi sumber daya (Supariasa et al., 2002).

\section{KETERBATASAN PENELITIAN}

Jumlah responden yang terdapat dalam data petugas Puskesmas tidak sesuai dengan keadaaan di lapangan karena responden pindah tempat/merantau. Responden yang siap menyediakan waktu untuk jalannya penelitian serta responden yang benar-benar merespon dengan baik terhadap peneliti.

Hal ini berkaitan dengan waktu yang cukup lama selama jalannya penelitian. Ketersediaan waktu, serta terbatasnya akses transpotasi merupakan salah satu hambatan yang ditemui selama penelitian berlangsung.

\section{KESIMPULAN DAN SARAN}

Cakupan pemberian ASI eksklusif pada bayi di Kecamatan Mapilli Kabupaten Polewali Mandar sedikit lebih besar dibanding cakupan ASI eksklusif di Indonesia. Ada pengaruh antara pemberian ASI eksklusif dengan edukasi IMD, tidak ada pengaruh antara ASI eksklusif dengan variabel luar (dukungan keluarga, dan pekerjaan ibu)

Perlu dilakukan penelitian lebih lanjut dengan menggunakan desain penelitian yang lebih baik seperti cohort prospektif dan besar sampel yang lebih banyak untuk mengurangi recall bias dan dapat mengendalikan faktorfaktor perancu serta mempertimbangkan aspek determinan penentuan ASI. Dengan pemberian ASI eksklusif, perlu adanya bimbingan dan edukasi secara berkala guna mendukung tercapainya ASI eksklusif. Pada Puskesmas Mapilli Kabupaten Polewali Mandar agar tetap mempertahankan prestasi dan meningkatkan cakupan pemberian ASI eksklusif.

\section{DAFTAR PUSTAKA}

Amin, N. U. R. A. (2015). Hubungan Antara Faktor Sosiodemografi dan Tinggi Badan Orangtua dengan Kejadian Stunting pada Balita Usia 6-23 Bulan di Kecamatan Sedayu Kabupaten Bantul Yogyakarta. Universitas Gadjah Mada. 
Badan Litbangkes. (2013). Riset Kesehatan Dasar (Riskesdas) 2013. In Lap Nas (Vol. 2013). Jakarta, Indonesia.

Brown, J. E. (2016). Nutrition Through The Life Cycle. Cengage Learning.

Candra, A., Puruhita, N., \& Susanto, J. C. (2011). Risk Factors of Stunting Among 1-2 Years Old Children in Semarang City. Media Medika Indonesiana, 45(3), 206-212.

Devi Asmarani. (2015). Uni Eropa dan UNICEF Bekerja Sama Untuk Meningkatkan Gizi Ibu dan Anak di Papua. Retrieved April 9, 2015, from UNICEF Indonesia website: http://indonesiaunicef.blogspot.com/2015 /02/uni-eropa-dan-unicef-bekerja-samauntuk.html

Dinkes Kabupaten Polewali Mandar. (2015). Profil Kesehatan Kabupaten Polewali Mandar Tahun 2015. In Polewali Mandar.

Giri, M. K. W., Muliarta, I. W., \& Wahyuni, N. D. S. (2013). Hubungan Pemberian ASI Eksklusif dengan Status Gizi Balita Usia 6-24 Bulan di Kampung Kajanan, Buleleng. JST (Jurnal Sains Dan Teknologi), 2(1), 184-192.

Grober, U. (2012). Mikronutrien: Penyelarasan Metabolik, Pencegahan, dan Terapi. In Jakarta: EGC.

Hidayah, F. (2013). ASI Eksklusif Sebagai Faktor Risiko Kejadian Stunting Pada Anak Usia 6-24 Bulan di Kota Yogyakarta. Universitas Gadjah Mada.

Jannah, A. M. (2016). Faktor-Faktor yang berhubungan dengan perilaku pemberian asi eksklusif pada bayi usia 6-12 bulan di Kelurahan Gerem Wilayah Kerja Puskesmas Grogol Kota Cilegon Tahun 2015. UIN Syarif Hidayatullah Jakarta: Fakultas Kedokteran dan Ilmu Kesehatan, 2016.

Kementrian Kesehatan Republik Indonesia. Peraturan Pemerintah Republik Indonesia Nomor 33 tahun 2012 tentang Pemberian Air Susu Ibu Eksklusif. , (2012).

Madise, N. J., Matthews, Z., \& Margetts, B. (1999). Heterogeneity of Child Nutritional Status Between Households: A Comparison of Six Sub-Saharan African Countries. Population Studies, 53(3), 331-343.1
Marques, R. F. S. V, Lopez, F. A., \& Braga, J. A. P. (2004). Growth of Exclusively Breastfed Infants in the First 6 Months of Life. Jornal De Pediatria, 80(2), 99-105.

Muchina, E. N., \& Waithaka, P. M. (2010). Relationship Between Breastfeeding Practices and Nutritional Status of Children Aged 0-24 Months in Nairobi, Kenya. African Journal of Food, Agriculture, Nutrition and Development, 10(4), 2358-2378.

Nilakesuma, A., Jurnalis, Y. D., \& Rusjdi, S. R. (2015). Hubungan Status Gizi Bayi dengan Pemberian ASI Ekslusif, Tingkat Pendidikan Ibu dan Status Ekonomi Keluarga di Wilayah Kerja Puskesmas Padang Pasir. Jurnal Kesehatan Andalas, 4(1), 37-44.

Paramashanti, B. A., Hadi, H., \& Gunawan, I. M. A. (2015). Hubungan Antara Praktik Pemberian ASI Eksklusif dan Stunting pada Anak Usia 6-23 Bulan di Indonesia. Jurnal Gizi Dan Dietetik Indonesia, 3(3), 170-182.

Pascale, K. N. A., Laure, N. J., \& Enyong, O. J. (2007). Factors Associated with Breast Feeding as Well as the Nutritional Status of Infants (0-12) Months: An Epidemiological Study In Yaounde, Cameroon. Pakistan Journal Nutrition, 6(3), 259-263.

Puskesmas Mapilli. (2015). Profil Kesehatan Puskesmas Mapilli. In PKM Mapilli.

Sawadogo, P. S., Martin-Prevel, Y., Savy, M., Kameli, Y., Traissac, P., Traoré, A. S., \& Delpeuch, F. (2006). An Infant and Child Feeding Index Is Associated with the Nutritional Status of 6-to 23-Month-Old Children In Rural Burkina Faso. The Journal of Nutrition, 136(3), 656-663.

Supariasa, I. D. N., Bakri, B., \& Fajar, I. (2002). Penilaian Status Gizi. In Jakarta: $E G C$ (Vol. 5).

Susanty, M., Kartika, M., Hadju, V., \& Alharini, S. (2012). Hubungan Pola Pemberian ASI dan MP-ASI dengan Gizi Buruk pada Anak 6-24 Bulan di Kelurahan Pannampu Makassar. Media Gizi Masyarakat Indonesia, 1(2), 97103.

Trisnawati, Y. (2017). Korelasi Waktu Pelaksanaan Inisiasi Menyusui Dini (IMD) Terhadap Lama Persalinan Kala III di Puskesmas Kalibagor Kabupaten 
Banyumas. Indonesia Jurnal Kebidanan, 1(1), 67-73.

Umeta, M., West, C. E., Verhoef, H., Haidar, J., \& Hautvast, J. G. A. J. (2003). Factors Associated with Stunting in Infants Aged 5-11 Months in the Dodota-Sire District, Rural Ethiopia. The Journal of Nutrition, 133(4), 1064-1069.

Wahdah, S., Juffrie, M., \& Huriyati, E. (2016). Faktor Risiko Kejadian Stunting pada Anak Umur 6-36 Bulan di Wilayah Pedalaman Kecamatan Silat Hulu, Kapuas Hulu, Kalimantan Barat. Jurnal Gizi Dan Dietetik Indonesia (Indonesian
Journal of Nutrition and Dietetics), 3(2), 119-130.

Wardani, P. (2009). Faktor-Faktor Penyebab Depresi Pasca Melahirkan pada Kelahiran Anak Pertama. Universitas Muhammadiyah Surakarta.

World Health Organization. (2010). Guidelines on HIV and Infant Feeding 2010: Principles and Recommendations for Infant Feeding in the Context of HIV and a Summary of Evidence. Geneva: World Health Organization. 